\title{
Do Multiple Body Modifications Alter Pain Threshold?
}

\author{
A. YAMAMOTOVÁ ${ }^{1}$, P. HRABÁK $^{1}$, P. HŘÍBEK $^{1}$, R. ROKYTA ${ }^{1}$ \\ ${ }^{1}$ Department of Normal, Pathological and Clinical Physiology, Third Faculty of Medicine, Charles \\ University, Prague, Czech Republic
}

Received March 22, 2017

Accepted November 3, 2017

\section{Summary}

In recent years, epidemiological data has shown an increasing number of young people who deliberately self-injure. There have also been parallel increases in the number of people with tattoos and those who voluntarily undergo painful procedures associated with piercing, scarification, and tattooing. People with self-injury behaviors often say that they do not feel the pain. However, there is no information regarding pain perception in those that visit tattoo parlors and piercing studios compared to those who don't. The aim of this study was to compare nociceptive sensitivity in four groups of subjects ( $n=105$, mean age 26 years, 48 women and 57 men) with different motivations to experience pain (i.e., with and without multiple body modifications) in two different situations; (1) in controlled, emotionally neutral conditions, and (2) at a "Hell Party" (HP), an event organized by a piercing and tattoo parlor, with a main event featuring a public demonstration of painful techniques (burn scars, hanging on hooks, etc.). Pain thresholds of the fingers of the hand were measured using a thermal stimulator and mechanical algometer. In HP participants, information about alcohol intake, self-harming behavior, and psychiatric history were used in the analysis as intervening variables. Individuals with body modifications as well as without body modifications had higher thermal pain thresholds at Hell Party, compared to thresholds measured at control neutral conditions. No such differences were found relative to mechanical pain thresholds. Increased pain threshold in all HP participants, irrespectively of body modification, cannot be simply explained by a decrease in the sensory component of pain; instead, we found that the environment significantly influenced the cognitive and affective component of pain.

\section{Key words}

Pain threshold - Tattoos - Piercing • Scarification • Body modifications

\section{Corresponding author}

A. Yamamotová, Department of Normal, Pathological and Clinical Physiology, Third Faculty of Medicine, Charles University, Ke Karlovu 4, 12000 Prague 2, Czech Republic. E-mail: yamamoto@lf3.cuni.cz

\section{Introduction}

Pain is defined as an unpleasant sensory and emotional experience associated with acute or potential tissue damage, or is described by such expressions. Pain is always subjective.

Like any definition, this one has its limitations. Pain, by definition, is unpleasant; however, there are individuals who intentionally caused pain to themselves without much suffering. In people with self-harming behaviors, physical pain can release and/or ameliorates mental tension or mental pain (Niedtfeld and Schmahl 2009). Deliberately induced pain may also help people with dissociative disorders return from a dissociated state to reality, or to escape from reality to a dissociated state (Fishbain et al. 2001). Another category includes those who voluntarily undergo pain during aesthetic changes to the body, such as tattoos, piercings, and scarification via cutting or burning.

Recent epidemiological data points to an increasing trend not only in the incidence of self-harm but also in the incidence of body modifications (Montgomery and Parks 2001, Laumann and Derrick 2006, Stirn et al. 2006). The steepest increase has been primarily seen among adolescents (Greydanus and Shek 2009). Although some associations have been found between the frequency of ear piercing and borderline personality disorders, these relationships were neither significant nor specific (Mi 1990). 
The motivational aspects for body modifications are many and diverse. Multiple body modifications are often associated with those searching for identity, a desire to be affiliated with a certain subculture, or as a manifestation of a specific type of non-verbal communication (Stirn et al. 2011). Additionally, those associated with body modifications are often regarded as having antisocial behaviors. Tattoos and piercings can express personal endurance to overcome pain as well as having an addictive character that might be linked to activation of the endogenous opioid system (Wohlrab et al. 2007).

Although the number of people with body modifications has significantly increased over the past several decades (Kluger 2015, Breuner et al. 2017), there have been no studies that test pain perception in these individuals. Therefore, the objective of this study was to compare pain threshold to thermal and mechanical stimuli in groups with different motivations to experience pain, i.e., (1) in control subjects without body modifications, and (2) in subjects with multiple body modification under two different conditions, (a) emotionally neutral and (b) emotionally intense. We tested the hypothesis that people with multiple body modifications have higher pain thresholds than those without body modifications.

\section{Methods}

\section{Participants and method}

Pain threshold was measured in 105 participants with different motivations to experience pain (with and without body modifications) (48 women and 57 men, mean age $26 \pm 8$ years) under two different conditions. The first part of experiment was conducted in familiar environments. Control subjects without body modifications ( $\mathrm{C} \mathrm{N}$, mostly medical students and their friends; $\mathrm{n}=18$ ) were tested under standard laboratory conditions; participants with body modifications (BM N, employees of tattoo parlors; $n=12$ ) were tested in a tattoo parlor setting. Both these groups were tested under what they perceived as natural and emotionally neutral conditions. The second part of experiment was conducted in a more emotionally charged environment, i.e., at a Hell Party (HP), which was characterized by the organizers as "a slightly rougher party for enthusiasts of piercings, tattoos, and other body modifications, as well as fans of BDSM (Bondage, Domination, Sadism and Masochism)."
Volunteers for research participation were recruited via internet advertisement in the program of a Hell Party. In this environment, two groups of volunteers were measured. One group consisted of participants with multiple body modifications (BM HP, $\mathrm{n}=45$ ), and the second group consisted of those without body modifications ( $\mathrm{C}$ HP, $\mathrm{n}=30$ ), but with an active interest in the experiences of the first group.

Given that pain perception can be influenced by factors other than the environment, volunteers at the HP filled out an anonymous questionnaire, regarding information that we considered relevant to the modulation of pain perception. These factors included: (1) alcohol or other substances that had been used prior to pain testing (amounts were in the range 1-2 glasses of beer or spirits, with none of the participants describing use/abuse of other addictive substances), (2) prescription medication use at the time of pain testing (results: hypnotics -1 , antidepressants -1 , analgesics -3 , and antibiotics -2 ), (3) previous or current psychiatric history, (4) self-injury behaviors (SIB), and (5) types of body modifications (tattoos, piercings, or scarification). The group with body modifications included those participants who had tattoos on more than $18 \%$ of the body surface (without other types of body modifications) or those with lesser tattooed area but in combination with another types of body modifications (numerous piercings and/or scarification). Demographic characteristics associated with the intervening variables are shown in Table 1.

Testing of the pain threshold at a Hell Party took place in an isolated space without the presence of other participants, just like in a laboratory or tattoo parlor. A portable pen-like thermal stimulator of our own production, operating on the principle of heating the skin with hot air in a range from $20-70^{\circ} \mathrm{C}$, was used to induce thermal pain (Fig. 1). In all settings, the pain threshold was measured on the dorsal aspect of the index, middle, and ring fingers of the non-dominant hand. The tip of thermal stimulator was located behind the nail bed. An average of the three measurements was used in the analysis. When the thermal stimulus reached threshold intensity, participants turned the apparatus off using a computer mouse. Mechanical pain threshold was measured on the same fingers using an electronic algometer (Somedic, Sweden), operating on an area of one square centimeter generating pressures in a range from $0-2,000 \mathrm{kPa}$. 
Table 1. Demographic characteristics for the subgroups defined by intervening variables.

\begin{tabular}{|c|c|c|c|c|c|c|c|c|c|}
\hline \multirow{3}{*}{$\frac{\text { Group }}{\operatorname{Sex}(\mathbf{N})}$} & & \multicolumn{4}{|c|}{ Neutral conditions } & \multicolumn{4}{|c|}{ Hell Party } \\
\hline & & \multicolumn{2}{|c|}{$\mathbf{C N}$} & \multicolumn{2}{|c|}{ BM N } & \multicolumn{2}{|c|}{ C HP } & \multicolumn{2}{|c|}{ BM HP } \\
\hline & & M (7) & F (11) & M (7) & F (5) & M (21) & F (9) & M (22) & F (23) \\
\hline Age (years) & & $30.7 \pm 14.6$ & $21.3 \pm 2.1$ & $28.6 \pm 2.8$ & $26.0 \pm 4.8$ & $29.4 \pm 10.3$ & $25.3 \pm 6.6$ & $24.9 \pm 4.9$ & $24.5 \pm 6.8$ \\
\hline Thermal pain $\left({ }^{\circ} \mathrm{C}\right)$ & & $47.8 \pm 4.6$ & $44.1 \pm 2.7$ & $47.4 \pm 8.1$ & $46.1 \pm 5.2$ & $53.8 \pm 5.8$ & $51.8 \pm 7.1$ & $57.4 \pm 6.1$ & $53.4 \pm 8.1$ \\
\hline Pressure pain (kPa) & & $951 \pm 263$ & $630 \pm 218$ & $1021 \pm 127$ & $664 \pm 119$ & $950 \pm 366$ & $751 \pm 242$ & $983 \pm 325$ & $922 \pm 349$ \\
\hline \multirow[t]{2}{*}{$\operatorname{Alcohol}(\mathbf{N})$} & Yes & 0 & 0 & 0 & 0 & 11 & 5 & 18 & 11 \\
\hline & No & & & & & 10 & 4 & 4 & 12 \\
\hline \multirow[t]{2}{*}{ SIB (N) } & Yes & 0 & 0 & 0 & 1 & 0 & 0 & 4 & 11 \\
\hline & No & & & 7 & 4 & & & 18 & 12 \\
\hline \multirow[t]{2}{*}{ Psychiatric history (N) } & Yes & 0 & 0 & 0 & 0 & 0 & 0 & 1 & 5 \\
\hline & No & & & & & & & 21 & 18 \\
\hline \multirow[t]{2}{*}{ Tattoo (N) } & Yes & 0 & 0 & 7 & 4 & 0 & 0 & 12 & 14 \\
\hline & No & & & 0 & 1 & & & 10 & 9 \\
\hline \multirow[t]{2}{*}{ Piercing (N) } & Yes & 0 & 0 & 6 & 5 & 0 & 0 & 16 & 19 \\
\hline & No & & & 1 & 0 & & & 6 & 4 \\
\hline \multirow[t]{2}{*}{ Scarification (N) } & Yes & 0 & 0 & 1 & 0 & 0 & 0 & 2 & 3 \\
\hline & No & & & 6 & 5 & & & 20 & 20 \\
\hline
\end{tabular}

C N: control subjects without body modifications measured in neutral settings; BM N: subjects with body modifications measured in neutral settings; C HP: control subjects without body modifications measured at a Hell Party; BM HP: subjects with body modifications measured at a Hell Party; F: female; M: male. Data are presented as Mean \pm SD.

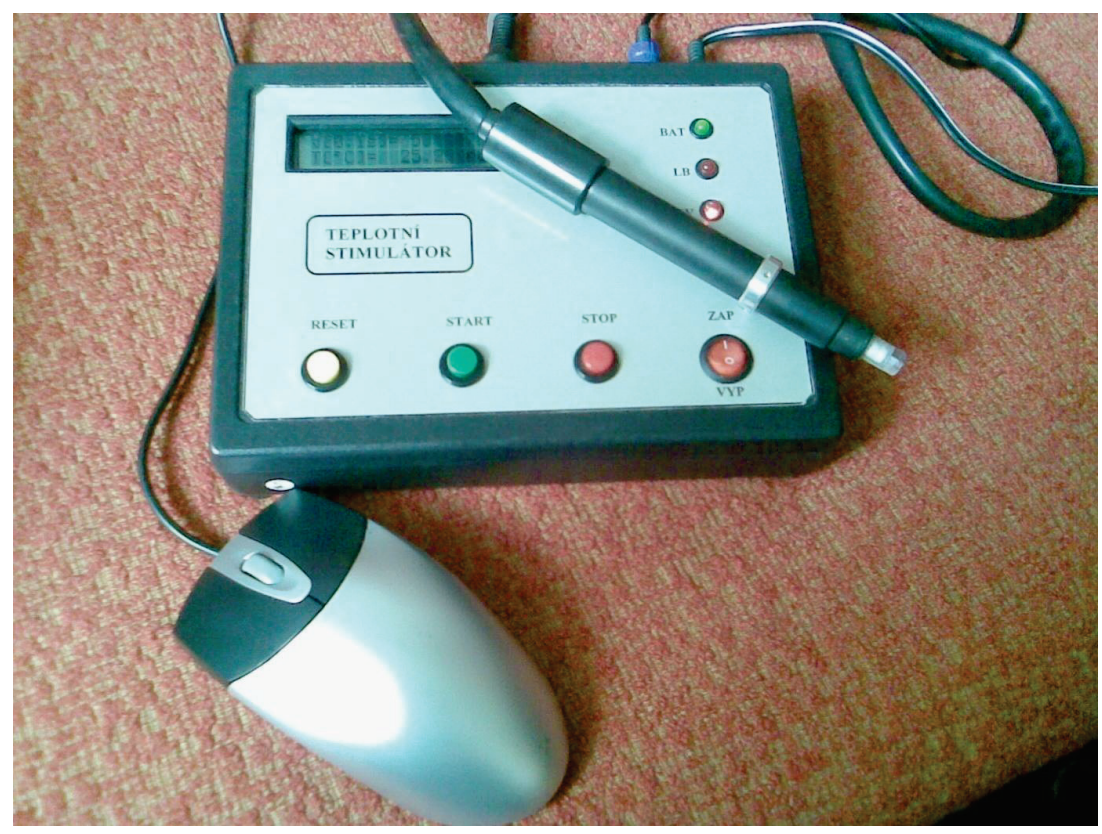

Fig. 1. The thermal stimulator device.

\section{Statistical analyses}

Differences in pain thresholds among control subjects and those with body modifications in two different experimental conditions were analyzed using the two-way ANOVA (four levels of factor group: $1^{\text {st }}$ group
- control subjects without body modifications measured in neutral settings $(\mathrm{C} \mathrm{N}) ; 2^{\text {nd }}$ group - subjects with body modifications measured in neutral settings (BM N); $3^{\text {rd }}$ group - control subjects without body modifications measured at a HP (C HP); $4^{\text {th }}$ group - subjects with body 
modifications measured at a HP (BM HP) and two levels of factor sex: men and women) separately for thermal and mechanical threshold. Where indicated, simple planned comparisons were used in post hoc analyses. Differences were considered significant if $\mathrm{p}<0.05$.

\section{Results}

\section{Thermal pain threshold}

A significant main effect of group $\left(\mathrm{F}_{(3,97)}=12.04\right.$, $\mathrm{p}=0.000001)$ indicated that both groups measured in emotionally neutral conditions (with or without body modifications) had significantly lower pain thresholds than the two other groups, which were measured under emotionally stimulating or intense conditions at the HP (Fig. 2). In spite of the fact that these two neutral conditions are different, they represented for our participants their habitual environment.

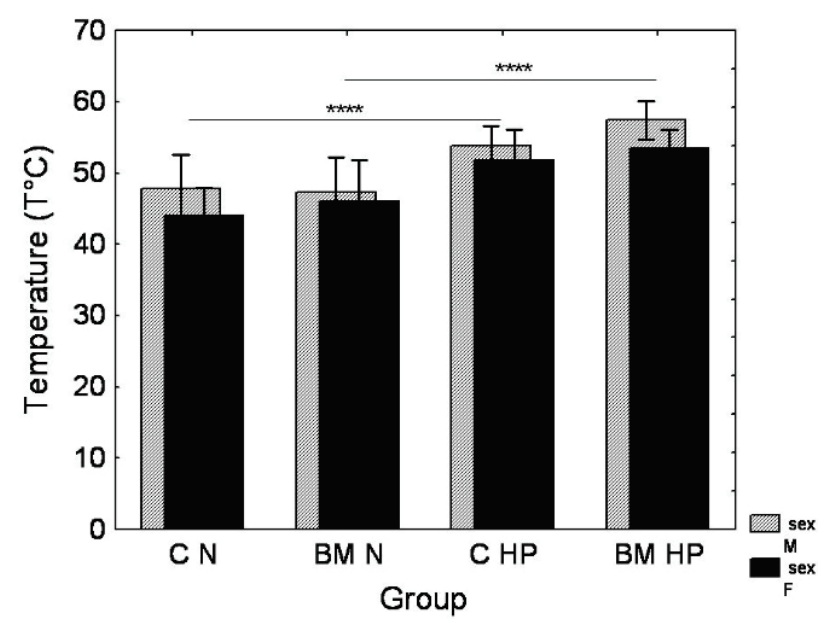

Fig. 2. Gender and group differences in thermal pain threshold. Abbreviations are the same as in Table 1 . Vertical bars denote 0.95 confidence intervals; $* * * * \mathrm{p}<0.00001$.

We observed a tendency toward lower pain thresholds in women compared to men $\left(\mathrm{F}_{(1,97)}=3.55\right.$, $\mathrm{p}=0.06$ ), but interaction of factors group $x$ sex was not significant $\left(\mathrm{F}_{(3,97)}=0.22, \mathrm{p}=0.88\right)$.

\section{Pressure pain threshold}

Contrary to thermal pain, sensitivity to pressure pain did not differ between groups $\left(\mathrm{F}_{(3,97)}=1.46, \mathrm{p}=0.23\right)$. A significant difference was found in factor sex $\left(\mathrm{F}_{(1,97)}=11.43, \mathrm{p}=0.001\right)$ with lower pain thresholds in women compared to men. Group $x$ sex interaction was also not significant $\left(\mathrm{F}_{(3,97)}=1.2, \mathrm{p}=0.31\right)$ (Fig. 3).

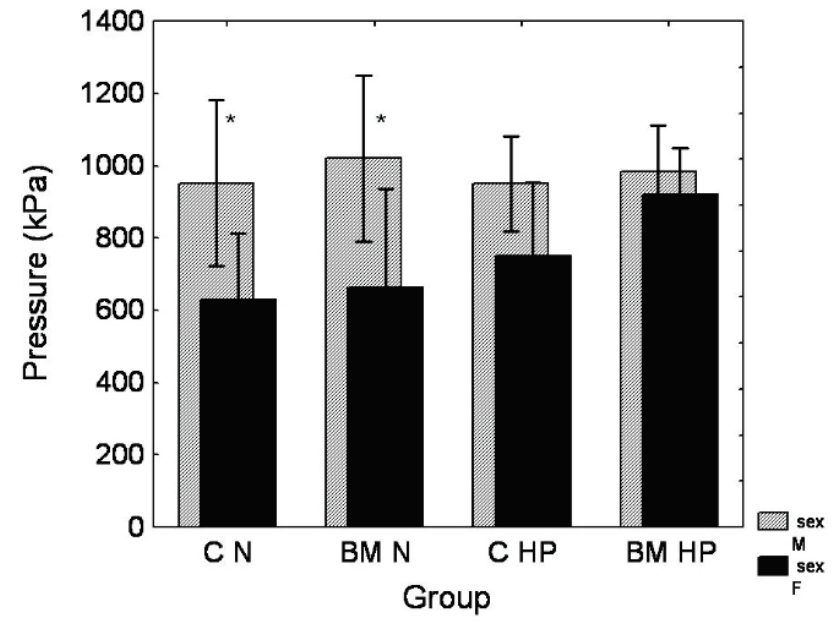

Fig. 3. Gender and group differences in pressure pain threshold. Abbreviations are the same as in Table 1. Vertical bars denote 0.95 confidence intervals; $* p<0.05 \mathrm{M}$ vs. F.

\section{Effect of intervening variables}

Since 45 persons, from the total number of 75 participants at the HP, stated alcohol use prior to pain testing, we analyzed the effect on pain thresholds separately using ANOVA with factors groups (with and without body modification) and alcohol intake. Regarding thermal pain threshold, alcohol intake had no significant effect (main effect of alcohol $\mathrm{F}_{(1,72)}=2.98$, $\mathrm{p}=0.09$ ) on either group of participants (group $x$ alcohol interaction $\mathrm{F}_{(1,72)}=0.73, \mathrm{p}=0.39$ ). Regarding pressure pain threshold, alcohol intake also had no significant effect $\left(F_{(1,72)}=1.45, p=0.23\right)$, however, the effect on the two groups were not the same (group $x$ alcohol interaction $\left.\mathrm{F}_{(1,72)}=4.7, \mathrm{p}=0.03\right)$, i.e. pain threshold was increased in participants with body modifications.

The effect of other intervening variables on pain thresholds in the HP participants with body modifications are summarized in Table 2.

In subjects with body modifications, thermal and pressure pain thresholds were influenced by self-injurious behavior (SIB) differently. SIB did not affect thermal pain threshold (main effect $\mathrm{F}_{(1,41)}=2.1, \mathrm{p}=0.16$ ) whereas SIB decreased pressure pain threshold (main effect $\left.\mathrm{F}_{(1,41)}=4.0, \mathrm{p}=0.05\right)$. This effect was probably caused by the larger number of women with self-injurious behavior in this group.

Current psychiatric comorbidity was associated with decreased thermal as well as pressure pain thresholds (main effects $\mathrm{F}_{(1,41)}=5.2, \quad \mathrm{p}=0.03$ and $\mathrm{F}_{(1,41)}=5.74, \mathrm{p}=0.02$, respectively). Again, this effect could have been caused by the larger number of women in this group. 
With regard to the nature of body modifications, thermal pain threshold was not influenced by any of them (main effect of tattoo $\mathrm{F}_{(1,41)}=0.98, \mathrm{p}=0.32$; main effect of piercing $\mathrm{F}_{(1,41)}=2.9, \mathrm{p}=0.1$, main effect of scarification $\left.\mathrm{F}_{(1,41)}=0.8, \mathrm{p}=0.38\right)$.

In contrast, pressure pain threshold was higher in persons with tattoos compared with those without tattoos $\left(\mathrm{F}_{(1,41)}=8.38, \mathrm{p}=0.006\right)$. However, scarification had the opposite effect; scarified participants had lower pressure threshold than those without scarifications $\left(\mathrm{F}_{(1,41)}=3.99\right.$, $\mathrm{p}=0.05)$. Piercing was not found to have any effect on pressure pain.

Table 2. Effect of intervening variables on heat and mechanical pain threshold in Hell Party participants with body modifications.

\begin{tabular}{|c|c|c|c|c|c|c|c|c|}
\hline \multicolumn{9}{|c|}{ ВM HP } \\
\hline \multirow{2}{*}{$\begin{array}{l}\text { Sex } \\
\text { Intervening } \\
\text { variable (IV) }\end{array}$} & & \multicolumn{2}{|c|}{ Males (22) } & \multicolumn{2}{|c|}{ Females (23) } & \multicolumn{3}{|c|}{$\operatorname{ANOVA}\left(\mathrm{F}_{(1,41)}\right)$} \\
\hline & & Yes & No & Yes & No & $\begin{array}{c}\text { Factor } \\
\text { of IV }\end{array}$ & Sex & $\begin{array}{c}\text { FIV x } \\
\text { Sex }\end{array}$ \\
\hline \multirow[t]{2}{*}{ Alcohol } & Thermal & $57.4 \pm 6.3$ & $57.4 \pm 5.7$ & $55.4 \pm 9.0$ & $51.6 \pm 7.1$ & $\begin{array}{c}\mathrm{F}=0.60, \\
\text { n.s. }\end{array}$ & $\begin{array}{c}\mathrm{F}=2.47, \\
\text { n.s. }\end{array}$ & $\begin{array}{c}\mathrm{F}=0.6 \\
\text { n.s. }\end{array}$ \\
\hline & Pressure & $1,022 \pm 343$ & $812 \pm 153$ & $1,092 \pm 264$ & $766 \pm 353$ & $\begin{array}{c}F=5.92 \\
p=0.02\end{array}$ & $\begin{array}{c}\mathrm{F}=0.01, \\
\text { n.s. }\end{array}$ & $\begin{array}{c}\mathrm{F}=0.28, \\
\text { n.s. }\end{array}$ \\
\hline \multirow[t]{2}{*}{ SIB } & Thermal & $60.3 \pm 5.0$ & $56.8 \pm 6.2$ & $55.3 \pm 8.8$ & $51.7 \pm 7.4$ & $\begin{array}{c}\mathrm{F}=2.06, \\
\text { n.s. }\end{array}$ & $\begin{array}{l}F=4.14, \\
p=0.05\end{array}$ & $\begin{array}{c}\mathrm{F}=0.00, \\
\text { n.s. }\end{array}$ \\
\hline & Pressure & $880 \pm 154$ & $1,006 \pm 351$ & $754 \pm 363$ & $1,076 \pm 264$ & $\begin{array}{l}F=4.04 \\
p=0.05\end{array}$ & $\begin{array}{c}\mathrm{F}=0.06, \\
\text { n.s. }\end{array}$ & $\begin{array}{c}\mathrm{F}=0.76, \\
\text { n.s. }\end{array}$ \\
\hline $\begin{array}{l}\text { Psychiatric } \\
\text { history }\end{array}$ & Thermal & 45.6 & $58.0 \pm 5.6$ & $49.1 \pm 2.6$ & $54.6 \pm 8.8$ & $\begin{array}{l}F=5.19 \\
p=0.03\end{array}$ & $\begin{array}{c}\mathrm{F}=0.00, \\
\text { n.s. }\end{array}$ & $\begin{array}{c}\mathrm{F}=0.75, \\
\text { n.s. }\end{array}$ \\
\hline \multirow{3}{*}{ Tattoo } & Pressure & 551 & $1,004 \pm 317$ & $604 \pm 249$ & $1,010 \pm 324$ & $\begin{array}{l}F=5.74, \\
p=0.02\end{array}$ & $\begin{array}{c}\mathrm{F}=0.03, \\
\text { n.s. }\end{array}$ & $\begin{array}{c}\mathrm{F}=0.02, \\
\text { n.s. }\end{array}$ \\
\hline & Thermal & $57.9 \pm 6.5$ & $57.0 \pm 5.8$ & $54.7 \pm 9.1$ & $51.3 \pm 6.3$ & $\begin{array}{c}\mathrm{F}=0.98, \\
\text { n.s. }\end{array}$ & $\begin{array}{c}F=3.93, \\
p=0.05\end{array}$ & $\begin{array}{c}\mathrm{F}=0.32, \\
\text { n.s. }\end{array}$ \\
\hline & Pressure & $1,022 \pm 378$ & $938 \pm 258$ & $1,097 \pm 264$ & $650 \pm 290$ & $\begin{array}{l}F=8.38 \\
p<0.01\end{array}$ & $\begin{array}{c}\mathrm{F}=1.34, \\
\text { n.s. }\end{array}$ & $\begin{array}{l}F=3.92, \\
p=0.05\end{array}$ \\
\hline Piercing & Thermal & $56.2 \pm 4.7$ & $60.7 \pm 8.4$ & $52.7 \pm 7.4$ & $57.0 \pm 11.7$ & $\begin{array}{c}\mathrm{F}=2.90, \\
\text { n.s. }\end{array}$ & $\begin{array}{c}\mathrm{F}=1.97, \\
\text { n.s. }\end{array}$ & $\begin{array}{c}\mathrm{F}=0.00, \\
\text { n.s. }\end{array}$ \\
\hline \multirow{3}{*}{ Scarification } & Pressure & $966 \pm 309$ & $1,030 \pm 391$ & $933 \pm 327$ & $868 \pm 497$ & $\begin{array}{c}\mathrm{F}=0.00, \\
\text { n.s. }\end{array}$ & $\begin{array}{c}\mathrm{F}=0.60, \\
\text { n.s. }\end{array}$ & $\begin{array}{c}\mathrm{F}=0.26, \\
\text { n.s. }\end{array}$ \\
\hline & Thermal & $50.5 \pm 6.9$ & $58.1 \pm 5.7$ & $54.7 \pm 10.3$ & $53.2 \pm 8.1$ & $\begin{array}{c}\mathrm{F}=0.80 \\
\text { n.s. }\end{array}$ & $\begin{array}{c}\mathrm{F}=0.01, \\
\text { n.s. }\end{array}$ & $\begin{array}{c}\mathrm{F}=1.74, \\
\text { n.s. }\end{array}$ \\
\hline & Pressure & $688 \pm 194$ & $1,013 \pm 323$ & $653 \pm 484$ & $962 \pm 321$ & $\begin{array}{l}F=3.99 \\
p=0.05\end{array}$ & $\begin{array}{c}\mathrm{F}=0.07, \\
\text { n.s. }\end{array}$ & $\begin{array}{c}\mathrm{F}=0.00, \\
\text { n.s. }\end{array}$ \\
\hline
\end{tabular}

Data are presented as Mean \pm SD; significant differences are in bold; n.s. nonsignificant.

\section{Discussion}

\section{Effect of body modification on nociception}

We expected that individuals repeatedly undergoing body modifications to have higher pain thresholds than subjects without body modifications and, as such, it would be easier for them to tolerate pain in an experimental setting. In both experimental conditions, neutral and emotional, we found differences in nociception among male and female participants. Gender differences that were seen were more associated with pressure than with thermal pain thresholds, with lower thresholds observed in women, which is in agreement with many other published studies (Lautenbacher and 
Rollman 1993, Fillingim 2000, Hashmi and Davis 2014).

\section{Effect of environment}

Regardless of whether participants at the HP had or did not have body modifications, their thresholds for thermal and pressure pain were similar. Thermal pain thresholds in both groups measured at the HP were significantly higher than in the corresponding groups measured in a natural, less emotionally charged environment, while no such differences were found in pressure pain thresholds. Thermal and mechanical pain sensitivity do not necessary have to correlate and differences can depend on the types of nerve fibers involved in pain transmission. C-fibers, which respond to noxious heat, play a major role in heat sensation, whereas A-fiber nociceptors are predominately heat and/or mechanosensitive (Dubin and Patapoutian 2010). Nociceptive stimulation of $\mathrm{C}$ fibers, triggered by thermal stimuli, correlates well with pain sensation, however, similar activation of $\mathrm{C}$ fibers caused by mechanical stimulation, which also activates A beta mechanoreceptors, does not necessarily produce any pain sensation (Hees and Gybels 1981).

Increased pain thresholds among HP participants can be explained by the influence of the emotionally charged or intense HP environment, which was perceived as an overall positive experience. Several experimental studies have shown that positive emotions as well as pleasant music can lead to pain reduction (Rhudy and Meagher 2001, Villemure and Bushnell 2002, Roy et al. 2008, Dubnar et al. 2012). Therefore, the HP party, as a body modification festival, with music and workshops demonstrating different techniques represented for both active and passive participants a very emotionally stimulating experience, which could have motivated them to exceed either their own borders or empathically share the pain experiences of others as well as sharing the emotional responses of others. Several fMRI studies have shown that during subjective experiences "to feel another's pain" requires, at least partially, activation of a mental representation of one's own pain, which is located mainly in the anterior cingulate and insular cortices, i.e. structures involved in processing the affective component of pain (Jackson et al. 2006, Zaki et al. 2007). Recently, Loggia et al. (2008) showed that empathy itself can alter the sensory component of pain.

\section{Consumption of alcohol}

Alcohol intake at the HP increased pressure pain thresholds, but not the thermal pain thresholds, in those with body modifications. Experimental results indicate that pressure pain stimulation might be more sensitive at detecting the pain-dampening effects of alcohol than electrical stimulation, the cold pressor test, and von Frey hairs (Horn-Hofmann et al. 2015). Since alcohol is known to have anxiolytic and stress-dampening effects, changes in pain perception might be attributable to changes in emotional state (Sayette 1999), which might be more responsive in participants with body modifications.

\section{Effect of psychiatric history}

Most works dealing with pain perception in patients with a spectrum of psychiatric disorders have described decreased pain sensitivity (Lautenbacher and Krieg 1994, Blumensohn et al. 2002, Papežová et al. 2005). Contrary to this, we found that our participants with a psychiatric diagnosis had reduced thermal and pressure pain thresholds. This result should be interpreted with caution considering the small number of subjects and the prevalence of women in this subgroup.

\section{Effect of scarification on pain threshold}

We showed that persons with scarification had a significantly reduced mechanical pain threshold. It could be a manifestation of hyperalgesia, due to a previous painful invasive technique. Among our participants, scarification, with the cutting of strips of skin for later formation of ornamental visible scars, probably represents the most painful procedure. Due to the small number of subjects with scarification, a physiological interpretation of their response is rather difficult; however, similar results were also obtained in participants with self-injury behaviors, which most frequently involved cutting; this could be explained by the similarity of techniques used during scarification and SIB. Regardless of the explanation, our results contradict many literature findings, which describe increased pain thresholds in subjects with SIB (Bunderla and Kumperščag 2015).

For people who deliberately self-injure, and thus voluntarily induce pain, it is believed that the neurobiological mechanism mainly involves a dysfunction of the opioid system, and to a lesser degree the serotonergic and dopaminergic systems (Stanley et al. 2010, Groschwitz and Plenar 2012). Many patients that repetitively self-mutilate seem to have developed a kind of addiction to the experience. The addiction appears to be based on a rapid reward effect that could be associated 
with either an up-regulation of opioid receptors in the central nervous system or they may suffer from premorbid changes in the activity of endogenous opioid system (Frecska and Arata 2002). The functions of opioid and dopaminergic systems are critical in motivation and analgesia. Since these systems interact with each other, the anatomical substrates of pleasure and pain can be considered as overlapping (Leknes and Tracey 2008).

One of the motivations of HP participants was to watch BDMS practices. Even though we did not gather information regarding participant masochistic behavior, we cannot rule-out this behavior as motivation for attending the HP. This behavior may also contribute to an increased pain threshold. It has been experimentally demonstrated, using fMRI, that brain areas activated in association with masochistic behavior were involved in sensorydiscriminative processing rather than affective pain processing, during receipt of painful stimuli delivered in the context of masochism (Kamping et al. 2016).

\section{Conclusions}

In this study, we showed that subjects with multiple body modifications did not differ in nociceptive sensitivity from control subjects without body modifications in control/neutral environments. When subjects both with multiple body modifications and control subjects without body modifications were tested in emotionally charged/intense environment (i.e. at a Hell Party) they also did not differ in nociceptive sensitivity.

The observation that participants with and without body modifications measured at the Hell Party had higher nociceptive thresholds than the corresponding groups measured in neutral environment leads us to conclude that increased nociceptive thresholds cannot be simply explained by reduced sensory perception caused by body modification. Instead it suggests that pain threshold in our participants was top-down modulated via affective and cognitive processes.

\section{Conflict of Interest}

There is no conflict of interest.

\section{Acknowledgements}

This study was supported by project PROGRES Q35 and $260388 / \mathrm{SVV} / 2017$.

\section{References}

BLUMENSOHN R, RINGLER D, ELI I: Pain perception in patients with schizophrenia. J Nerv Ment Dis 190: 481-483, 2002.

BREUNER CC, LEVINE DA, AAP COMMITTEE ON ADOLESCENCE: Adolescent and young adult tattooing, piercing, and scarification. Pediatrics 140: e20171962, 2017.

BUNDERLA T, KUMPERŠČAK HG: Altered pain perception in self-injurious behavior and the association of psychological elements with pain perception measures: a systematic review. Psychiatr Danub 4: 346-354, 2015.

DUBIN AE, PATAPOUTIAN A: Nociceptors: the sensors of the pain pathway. J Clin Invest 120: 3760-3772, 2010.

DUNBAR RI, KASKATIS K, MACDONALD I, BARRA V: Performance of music elevates pain threshold and positive affect: implications for the evolutionary function of music. Evol Psychol 10: 688-702, 2012.

FILLINGIM RB: Sex, gender, and pain: women and men really are different. Curr Rev Pain 4: 24-30, 2000.

FISHBAIN DA, CUTLER RB, ROSOMOFF HL, ROSOMOFF RS: Pain-determined dissociation episodes. Pain Medicine 2: 216-224, 2001.

FRECSKA E, ARATO M: Opiate sensitivity test in patients with stereotypic movement disorder and trichotillomania. Prog Neuropsychopharmacol Biol Psychiatry 26: 909-912, 2002.

GREYDANUS DE, SHEK D: Deliberate self-harm and suicide in adolescents. Keio J Med 58: 144-151, 2009.

GROSCHWITZ RC, PLENER PL: The neurobiology of non-suicidal self-injury (NSSI): a review. Suicidol Online 3: 24-32, 2012.

HASHMI JA, DAVIS KD: Deconstructing sex differences in pain sensitivity. Pain 155: 10-13, 2014.

HORN-HOFMANN C, BÜSCHER P, LAUTENBACHER S, WOLSTEIN J: The effect of nonrecurring alcohol administration on pain perception in humans: a systematic review. J Pain Res 8: 175-187, 2015.

JACKSON PL, RAINVILLE P, DECETY J: To what extent do we share the pain of others? Insight from the neural bases of pain empathy. Pain 25: 5-9, 2006. 
KAMPING S, ANDOH J, BOMBA IC, DIERS M, DIESCH E, FLOR H: Contextual modulation of pain in masochists: involvement of the parietal operculum and insula. Pain 157: 445-455, 2016.

KLUGER N: Epidemiology of tattoos in industrialized countries. Curr Probl Dermatol 48: 6-20, 2015.

LAUMANN AE, DERRICK AJ: Tattoos and body piercings in the United States: A national data sets. $J$ Am Acad Dermatol 55: 413-421, 2006.

LAUTENBACHER S, KRIEG JC: Pain perception in psychiatric disorders: a review of the literature. J Psychiatr Res 28: 109-122, 1994.

LAUTENBACHER S, ROLLMAN GB: Sex differences in responsiveness to painful and non-painful stimuli are dependent upon the stimulation method. Pain 53: 255-264, 1993.

LEKNES S, TRACEY I: A common neurobiology for pain and pleasure. Nature Rev Neurosci 9: 314-320, 2008.

LOGGIA ML, MOGIL JS, BUSHNELL MC: Empathy hurts: compassion for another increases both sensory and affective components of pain perception. Pain 136: 168-176, 2008.

MEAGHER MW, ARNAU RC, RHUDY JL: Pain and emotion: effects of affective picture modulation. Psychosom Med 63: 79-90, 2001

MI AH: Borderline personality and multiple earrings: a possible correlation? Am J Psychiatry 147: 1251, 1990.

MONTGOMERY DF, PARKS D: Tattoos: counseling the adolescent. J Pediatr Health Care 15: 14-19, 2001.

NIEDTFELD I, SCHMAHL C: Emotion regulation and pain in borderline personality disorder. Curr Psychiatry Rev 5: 48-54, 2009.

PAPEZOVÁ H, YAMAMOTOVÁ A, UHER R: Elevated pain threshold in eating disorders: physiological and psychological factors. J Psychiatr Res 39: 431-438, 2005.

ROY M, PERETZ I, RAINVILLE P: Emotional valence contributes to music-induced analgesia. Pain 134: 140-147, 2008.

SAYETTE MA: Does drinking reduce stress? Alcohol Res Health 23: 250-255, 1999.

STANLEY B, SHER L, WILSON S, EKMAN R, HUANG YY, MANN JJ: Non-suicidal self-injurious behavior, endogenous opioids and monoamine neurotransmitters. J Affect Disord 124: 134-140, 2010.

STIRN A, HINZ A, BRÄHLER E: Prevalence of tattooing and body piercing in Germany and perception of health, mental disorders, and sensation seeking among tattooed and body-pierced individuals. J Psychiatry Res 60: 531-534, 2006.

STIRN A, ODDO S, PEREGRINOVA L, PHILIPP S, HINZ A: Motivations for body piercings and tattoos - the role of sexual abuse and the frequency of body modifications. Psychiatry Res 190: 359-363, 2011.

VAN HEES J, GYBELS J: C nociceptor activity in human nerve during painful and non painful skin stimulation. J Neurol Neurosurg Psychiatry 44: 600-607, 1981.

VILLEMURE C, BUSHNELL MC: Cognitive modulation of pain: how do attention and emotion influence pain processing? Pain 95: 195-199, 2002.

WOHLRAB S, STAHL J, KAPPELER PM: Modifying the body: motivations for getting tattooed and pierced. Body Image 4: 87-95, 2007.

ZAKI J, OCHSNER KN, HANELIN J, WAGER TD, MACKEY SC: Different circuits for different pain: patterns of functional connectivity reveal distinct networks for processing pain in self and others. Soc Neurosci 2: 276-291, 2007. 